\title{
APLIKASI PEMBELAJARAN RAMBU-RAMBU LALU LINTAS MENGGUNAKAN METODE FINITE STATE MACHINE (FSM) BERBASIS WEB
}

\author{
Dahlan Abdullah', Erlina ${ }^{2}$, Cut Ita Erliana ${ }^{3}$, Defi Irwansyah ${ }^{3}$, Muhammad \\ Zarlis $^{4}$, Elviwani ${ }^{5}$, H Hartono ${ }^{6}$ \\ ${ }^{1,2}$ Program Studi Teknik Informatika, Universitas Malikussaleh, Aceh, Indonesia \\ 3 Program Studi Teknik Industri, Universitas Malikussaleh, Aceh, Indonesia \\ ${ }^{4,5}$ Program Studi Ilmu Komputer, Universitas Sumatera Utara, Medan, Indonesia \\ ${ }^{6}$ Program Studi Ilmu Komputer, STMIK IBBI, Medan, Indonesia \\ ${ }^{1}$ dahlan@unimal.ac.id, ${ }^{3}$ cutitha@unimal.ac.id, ${ }^{4}$ mzarlis2000@yahoo.com, \\ 5 elviwani@usu.ac.id, ${ }^{6}$ hartonoibbi@gmail,com,
}

\begin{abstract}
ABSTRAK
Banyak kecelakaan yang terjadi saat ini disebabkan oleh kurangnya pemahaman masyarakat mengenai rambu-rambu lalu lintas. Rambu lalu lintas merupakan salah satu perlengkapan jalan yaitu lambang, huruf, angka kalimat atau perpaduan antaranya. Rambu sangat penting bagi pemakai jalan sebagai alat untuk pentunjuk dan peringatan pada pengguna di jalan. Untuk itu perlu diberikan pemahaman kepada masyarakat tersebut. Cara yang paling mudah adalah dengan memberikan pembelajaran berbentuk game tentang pembelajaran ramburambu lalu lintas. Kegiatan Penelitian ini mengembangkan game pembelajaran RambuLalu Lintas Berbasis Web dengan menggunakan bahasa pemrograman PHP dan MySQL sebagai basis data. Dan menerapkan metode Finite State Machine untuk proses alur kontrol permainan yang terdiri dari 4 level, dimana player akan melengkapi jawaban dari setiap levelagar dapat melanjutkan ke level berikutnya. Hasil dari game ini dapat memberikan pengetahuan tentang rambu-rambu lalu lintas yang lebih menarik untuk dipelajari dan menyadari pentingnya menaati rambu-rambu lalu lintas.
\end{abstract}

Kata kunci: PHP, MySQL, Finite State Machine. 


\section{PENDAHULUAN}

\subsection{Latar Belakang}

Rambu lalu lintas adalah salah satu dari perlengkapan jalan, berupa lambang, huruf, angka kalimat atau perpanduan. Diantaranya rambu peringatan, rambu perintah, rambu larangan, rambu petunjuk bagi pemakai jalan. Rambu lalu lintas digunakan sebagai pengguna di jalan yang baik. Rambu sangat penting bagi pemakai jalan sebagai alat untuk petunjuk dan peringatan pada pengguna di jalan.

Rambu lalu lintas ini memberi definisi kepada masyarakat bagaimana isi, dan arti dari simbol rambu lalu lintas dan peraturan yang sudah di tetapkan dalam undang-undang lalu lintas. Akan tetapi sebagaian masyarakat dijalan banyak yang melanggar rambu lalu lintas. Hal ini karena kurangnya kesadaran masyarakat untuk menaati peraturan lalu lintas. Tingkat kepatuhan secara stereotip juga berbedabeda. Bukan hanya di sebabkan oleh fakor lingkungan dan budaya, akan tetapi juga oleh karena pendidikan yang berbeda. Dari tingkat kesadaran hukum yang relatif rendah menyebabkan kewajiban hukum dan perundang-undang di bidang lalu lintas. (Irwan Andriyanto : 2016).Menyadari akan pentingnya kegunaan sebuah rambu lalu lintas. Maka dari itu peneliti akan membangun sebuah aplikasi pembelajaran rambu-rambu lalu lintas. Yang memudahkan masyarakat untuk mengetahui rambu-rambu lalu lintas berbasis web.

Pembelajaran rambu-rambu lalu lintas berbasis web ini bisa diakses oleh semua kalangan sehingga nantinya lebih mengenal dan memahami rambu-rambu lalu lintas saat berkendara. Aplikasi ini dibuat menggunakan metode Finite State Machine (FSM) untuk proses alur control permainan game pembelajaran ini. Berdasarkan sifatnya, metode FSM ini sangat cocok digunakan sebagai basis perancangan perangkat lunak pengendalian yang bersifat reaktif dan real time. Salah satu keuntungan nyata penggunaan FSMadalah kemampuannya dalam mendekomposisi aplikasi yang relative besar dengan hanya menggunakan sejumlah kecil item state. Selain untuk bidang kontrol, penggunaan metode ini pada kenyataannya juga umum digunakan sebagai basis untuk perancangan protokol-protokol komunikasi, perancangan perangkat lunak game, aplikasi Web HTMLdan sebagainya. Sehingga nantinya akan menjadikan sebuah game yang berkonten berpendidikan berbasis webdan sebagai media pembelajaran untuk meningkatkan hasil belajar dengan menyajikan game pertanyaan dalam permainan. Hal ini diharapkan dapat menjadi media suatu pembelajaran 
yang menyenangkan saat mendapat materi dan memotifasi dalam belajar lebih banyak lagi rambu-rambu lalu lintas agar menjadi lebih mematuhi peraturan berlalu lintas.(Irwan Andriyanto : 2016).

\section{METODOLOGI PENELITIAN}

\subsection{Analisa}

Analisa sistem bertujuan untuk mengidentifikasi permasalahanpermasalahan yang ada pada sistem, dimana aplikasi yang dibangun meliputi lingkungan operasi, user dan elemen-elemen yang terkait. Analisa terhadap sistem diperlukan sebagai dasar untuk tahapan perancangan sistem, yaitu meliputi desain sistem, perancangan dan implementasi sistem.

\subsection{Cara Kerja FSM}

Dalam FSM masing-masing karakter menempati satu state. Biasanya, tindakan atau perilaku yang terkait dengan masing-masing state. Jadi selama karakter tetap dalam keadaan itu, ia akan terus melakukan tindakan yang sama. State terhubung bersama oleh transition. Setiap transition mengarah dari satu state ke state lain yang biasanya state tujuan state target ini disebut dengan action dan masingmasing memiliki seperangkat kondisi yang terkait. Jika permainan menentukan bahwa kondisi transition terpenuhi, maka karakter berubah dari state ke state target (action) melalui transition itu.

Dalam Game ini proses Finite State Machine (FSM) berjalan dengan mendapatkan aturan benar dan salah, ketika kondisi benar kemudian akan ditampilakan lanjutan state atau pertanyaan lanjutan dan selain dari jawaban benar maka akan melakukan pengulangan state / mengulangi pertanyaan.Berikut diagram rancangan game dengan Finite State Machine (FSM) :

Inisialisasi input :

Salah: $0 \rightarrow$ Kembali

Benar: $1 \rightarrow$ Next State 


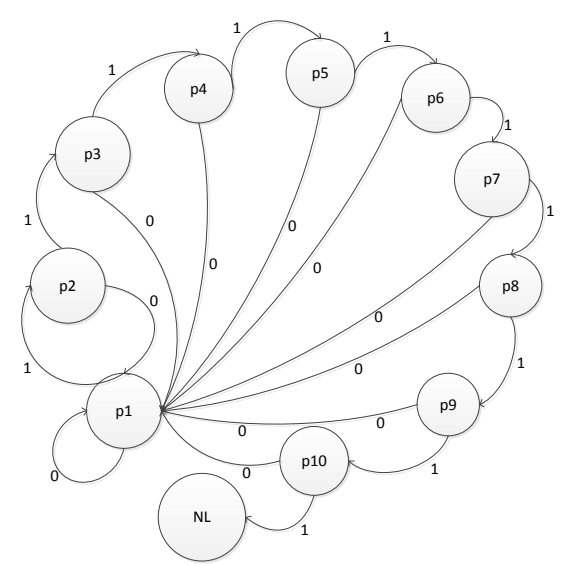

Gambar 1. Diagram Finite State Machine (FSM)

Dari diagram FSM diatas dapat dituliskan ke dalam tabel transisi sebagai berikut :

Tabel 1. Transisi Finite State Machine (FSM)

\begin{tabular}{|c|c|c|}
\hline \multirow{2}{*}{ Current State } & \multicolumn{2}{|c|}{ Next State } \\
\cline { 2 - 3 } & 0 & 1 \\
\cline { 2 - 3 } & P1 & P2 \\
P1 & P1 & P3 \\
P2 & P1 & P4 \\
P3 & P1 & P5 \\
P4 & P1 & P6 \\
P5 & P1 & P7 \\
P6 & P1 & P8 \\
P7 & P1 & P9 \\
P8 & P1 & P10 \\
P9 & P1 & NL \\
P10 & - & - \\
NL & &
\end{tabular}

Penjelasan tabel :

1. P1 merupakan pertanyaan 1 : jika pertanyaan 1 dapat dijawab dengan benar, maka next state adalah pertanyaan 2 dan jika pertanyaan 1 dijawab dengan jawaban salah maka akan kembali ke pertanyaan 1 .

2. P2 merupakan pertanyaan 2 : jika pertanyaan 2 dapat dijawab dengan benar, maka next state adalah pertanyaan 3 dan jika pertanyaan 2 dijawab dengan jawaban salah maka akan kembali ke pertanyaan 1 .

3. P3 merupakan pertanyaan 3 : jika pertanyaan 3 dapat dijawab dengan benar, maka next state adalah pertanyaan 4 dan jika pertanyaan 3 dijawab dengan jawaban salah maka akan kembali ke pertanyaan 1 . 
4. P4 merupakan pertanyaan 4 : jika pertanyaan 4 dapat dijawab dengan benar, maka next state adalah pertanyaan 5 dan jika pertanyaan 4 dijawab dengan jawaban salah maka akan kembali ke pertanyaan 1 .

5. P5 merupakan pertanyaan 5 : jika pertanyaan 5 dapat dijawab dengan benar, maka next state adalah pertanyaan 6 dan jika pertanyaan 5 dijawab dengan jawaban salah maka akan kembali ke pertanyaan 1 .

6. P6 merupakan pertanyaan 6 : jika pertanyaan 6 dapat dijawab dengan benar, maka next state adalah pertanyaan 7 dan jika pertanyaan 6 dijawab dengan jawaban salah maka akan kembali ke pertanyaan 1 .

7. P7 merupakan pertanyaan 7 : jika pertanyaan 7 dapat dijawab dengan benar, maka next state adalah pertanyaan 8 dan jika pertanyaan 7 dijawab dengan jawaban salah maka akan kembali ke pertanyaan 1 .

8. P8 merupakan pertanyaan 8 : jika pertanyaan 8 dapat dijawab dengan benar, maka next state adalah pertanyaan 9 dan jika pertanyaan 8 dijawab dengan jawaban salah maka akan kembali ke pertanyaan 1 .

9. P9 merupakan pertanyaan 9 : jika pertanyaan 9 dapat dijawab dengan benar, maka next state adalah pertanyaan 10 dan jika pertanyaan 9 dijawab dengan jawaban salah maka akan kembali ke pertanyaan 1 .

10. P10 merupakan pertanyaan 10 : jika pertanyaan 10 dapat dijawab dengan benar, maka next state adalah level selanjutnya dan jika pertanyaan 10 dijawab dengan jawaban salah maka akan kembali ke pertanyaan 1.

11. NL merupakan next level

Pada game ini ada beberapa pertanyaan, setiap pertanyaan akan bernilai dengan jumlah benar dibagi jumlah pertanyaan kemudian dikali 100 seperti rumus berikut:

$$
\frac{\text { Jumlah pertanyaan benar }}{\text { Jumlah pertanyaan }} \times 100=\text { nilai }
$$

Contoh: $\frac{6}{10} \times 100=60$

atau $\frac{4}{10} \times 100=40$

Note :

Jawaban Benar $>$ Jawaban Salah $=$ Level Selanjutnya

Jawaban Benar $<$ Jawaban Salah $=$ Tetap di level yang sama

Keterangan :

Jika jawaban pertanyaan benar lebih banyak dari jumlah jawaban pertanyaan yang salah maka sistem akan melanjutkan ke level selanjutnya, namun apabila jawaban dari pertanyaan benar lebih sedikit 
dari jawaban dari pertanyaan salah maka sistem akan mengulangi ke pertanyaan pertama yang berarti sistem tidak dapat melanjutakan ke level selanjutnya.

\section{ANALISA DAN PEMBAHASAN}

\subsection{Perancangan Sistem}

Perancangan perangkat lunak penyelesaian aplikasi pengenalan dan pembelajaran bagun ruang ini menggunakan Eclipse yang merupakan peranti pengembangan aplikasi yang menggunakan bahasa pemrogramanjava. Untuk database yang berfungsi sebagai tempat penyimpanan digunakan SQLite Manager. Berikut merupakan rancangan menggunakan usecase diagram yang akan menjelaskan secara sederhana bagaimana aplikasi ini berjalan:

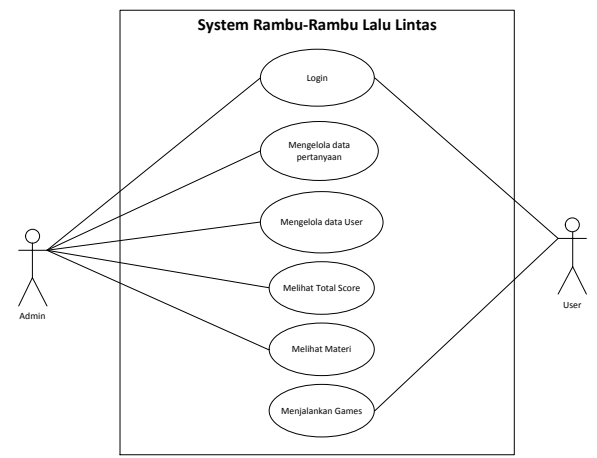

Gambar 2. Diagram usecase

Diagram use case menunjukkan cara kerja sistem secara umum. Dalam diagram ini ditampilkan dua buah actor yaitu admin dan user.Admin berinteraksi dengan fungsi login, mengelola data pertanyaan, mengelola data user, melihat total score, melihat materi dan logout. User dapat berinteraksi dengan fungsi login, melihat materi, menjalankan games dan logout.

\subsection{User Interface}

Pada user interface ditampilkan desain grafis antarmuka. Adapun form tampilan dalam aplikasi ini, antara lain tampilan splash screen, menu utama, menu data tanaman, menu data penyakit,menu kategori tanaman sayuran, menu kategori tanaman buah, menu kategori tanaman rempah, menu kategori penyakit dalam, menu kategori penyakit luar dan menu tentang. 


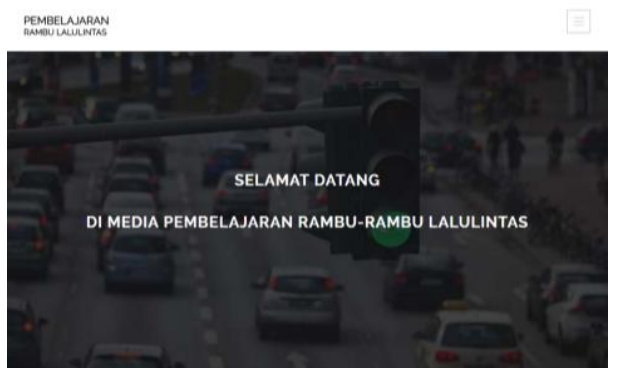

Gambar 25. Tampilan Splash Screen

Splash screen merupakan layar pembuka saat pertama kali aplikasi dibuka. Splash screen juga memiliki fungsi sebagai loader (pemuat) database yang digunakan, sehingga ketika aplikasi dijalankan, aplikasi tersebut hanya perlu membuka database tanpa perlu memuatnya telebih dahulu.

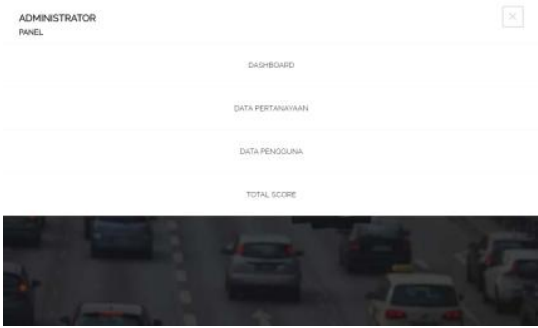

Gambar 3. Tampilan Menu Admin

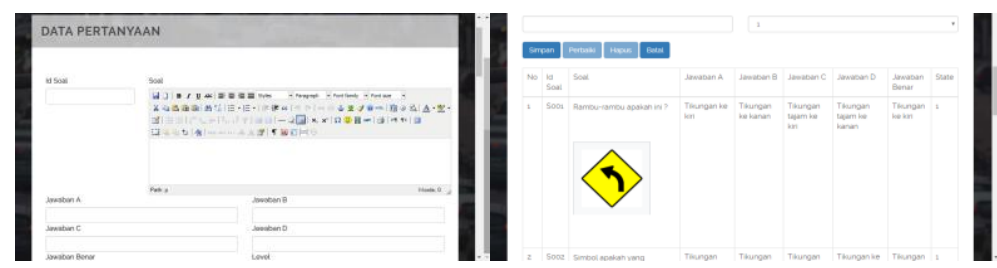

Gambar 26.Tampilan Data Pertanyaan

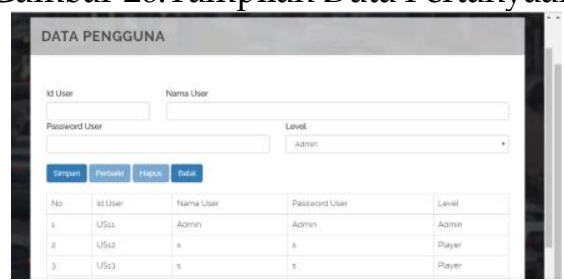

Gambar 27. Tampilan Data User 


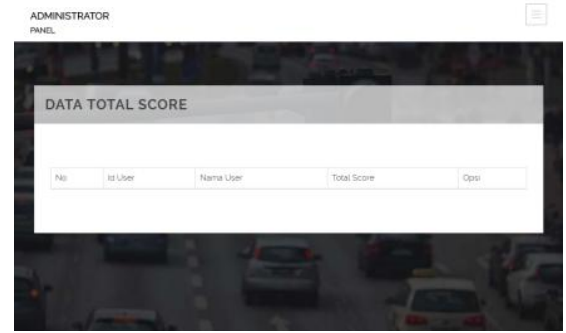

Gambar 28. Tampilan Score
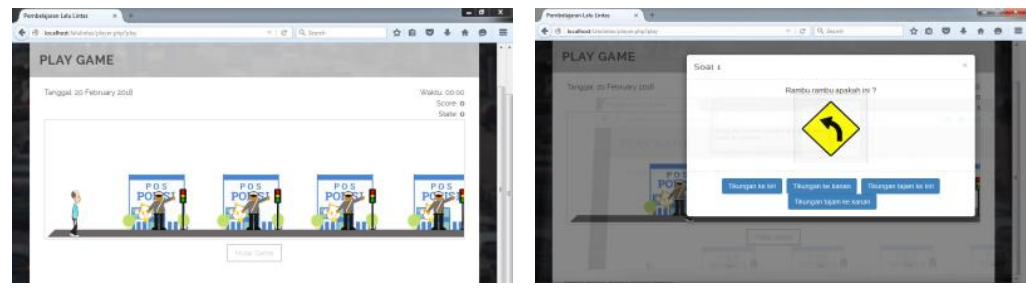

Gambar 29. Tampilan Permainan
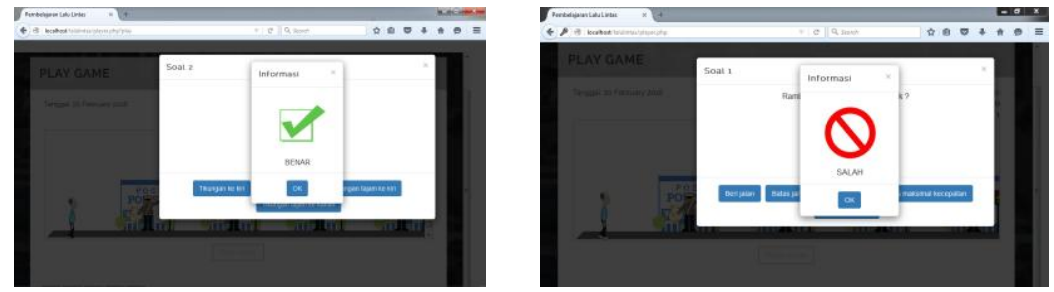

Gambar 30. Tampilan Jawaban

\section{KESIMPULAN}

Adapun kesimpulan yang diperoleh dari penelitian ini, adalah sebagai berikut:

1. Aplikasi berbasis Web ini bertujuan sebagai media pembelajaran kepada masyarakat dalam mengenal dan mempelajari arti ramburambu lalu lintas agar lebih mematuhi tata cara berlalu lintas yang baik dan benar. 
2. Pembelajaran rambu-rambu lalu lintas ini di buat menggunakan Finite State Machine (FSM) dalam menyelesaikan permainan dengan menjawab pertanyaan.

3. Dalam aplikasi ini disisipkan soal-soal yang harus dijawab pengguna untuk mengukur pengetahuan dalam berlalu lintas.

4. Permainan akan berhasil jika telah menyelesaikan permainan dengan menjawab pertanyaan dalam setiap level.

5. Permainan ini dibuat dengan pertanyaan bergambar untuk menarik pengguna dalam menjawab semua pertanyaan namun aplikasi akan mengulang keawal pertanyaan apabila terjadi kesalahan dalam menjawab pertanyaan.

\section{DAFTAR PUSTAKA}

Abdullah, Dahlan., dkk. 2015, Game Edukasi Berbasis Role Playing Game dengan Metode Finite State Macine (FSM), Informatika. Universitas Malikussaleh Lhoksemawe.

A.S., Rosa, Shalahuddin, M., 2013, RekayasaPerangkat Lunak Terstruktur dan Berorientasi Objek, Informatika, Bandung.

Andriyanto, Irwan., 2016, Game Edukasi Pengenalan Rambu-Rambu Lalu Lintas Untuk Anak SD, Skripsi. Universitas Muhammadiyah, Surakarta.

Huda, A.S., 2016, Game Edukasi Cepat Tepat Dengan Metode Finite State Machine pada Smartphone, Skripsi. Islam Negri Maulana Malik Ibrahim, Malang.

Muharraran, Maryam., 2014, Aplikasi Pembelajaran Dasar Aksara Sunda Berbasis Android, Program Studi Sistem Informasi, Universitas Komputer Indonesia, Bandung.

Pratama, Dargawan Aditia., 2014, Aplikasi Edukasi Bagi Anak Usia Dini Berbasis Mobile Android, Program Studi Sistem Informasi, Universitas Komputer Indonesia, Bandung.

Reza, Baihaqi., 2015, Game Edukasi Berbasis Role Playing Game Dengan Metode Finite State Machine, Skripsi. Universitas Malikussaleh, Lhoksemawe.

Rostianingsih, Silvia, dkk., 2011, Game Simulasi Finite State Machine untuk Pertanian dan Perternakan, Informatika, Kristen Petra, Surabaya.

Sidik, Fajri., 2016, Implemantasi Algoritma Multiplicative Congruential Random Number Generator Pada Try Out SMA (Sekolah Menengah Atas) Berbasis Web, Skripsi, Universitas Malikussaleh, Lhoksemawe. 
Sugiman, V.R, dkk., 2012, Pengembangan Aplikasi Rambu-Rambu Lalu Lintas berbasis Android Menggunakan Metode Prototyping, Sekolah Tinggi Teknologi, Garut vol 11.

Suyanto, Wardan., 2012, Pengenalan Rambu-Rambu Lalu Lintas Bagi Siswa SMK Dalam Rangka Membentuk Prilaku Tertip Berlalu Lintas, Yogyakarta. 